\title{
Os programas suplementares do FNDE voltados à ampliação da jornada nas escolas: uma análise da crescente apropriação da racionalidade privatista no currículo do ensino médio em tempo integral ${ }^{1}$
}

\author{
Micilane Pereira de Araújo ${ }^{2}$ \\ Jamerson Antônio de Almeida da Silva ${ }^{3}$
}

\section{Resumo}

Este artigo visa analisar o Programa Ensino Médio Inovador e a Política de Fomento às Escolas de Ensino Médio em Tempo Integral, ambos vinculados à política de reestruturação do currículo e ampliação da jornada escolar. Para situarmos o nosso estudo, tomaremos o exemplo da matriz curricular da rede de ensino do estado de Pernambuco, concentrando a análise na Parte Diversificada e nas Atividades Complementares, espaços onde as duas políticas em questão vêm atuando. Observamos que essas políticas vinculam qualidade educacional às políticas de resultados e à flexibilização curricular, circunstâncias que sinalizam para uma progressiva descaracterização da unicidade entre trabalho, ciência, tecnologia e cultura.

Palavras-chave: Políticas Curriculares; Ensino Médio Integral; Reforma do Ensino Médio.

Los programas suplementarios del FNDE orientados a la ampliación de la jornada escolar: un análisis de la creciente apropiación de la racionalidad privatista en el currículo de la escuela secundaria a tiempo completo

\section{Resumen}

Este artículo tiene como objetivo analizar el Programa de Educación Media Innovadora y la Política de Fomento a las Escuelas de Secundaria en Tiempo Integral, ambos vinculados a la política de reestructuración del currículo y ampliación de la jornada escolar. Para situar nuestro estudio, tomaremos el ejemplo de la matriz curricular de la red de enseñanza del estado de Pernambuco, concentrando el análisis en la Parte Diversificada y en las Actividades Complementarias, espacios donde las dos políticas en cuestión vienen actuando. Observamos que esas políticas vinculan calidad educativa a las políticas de resultados y a la flexibilización curricular, circunstancias que señalan para una progresiva descaracterización de la unicidad entre trabajo, ciencia, tecnología y cultura. Palabras clave: Políticas Curriculares; Educación Secundaria Integral; Reforma de la Escuela Secundaria.

\section{Introdução}

A Lei de Diretrizes e Bases da Educação Nacional, LDBEN, n. 9.394/96, fruto de um longo processo de negociações em favor da escola pública democrática, define como finalidades do Ensino Médio a preparação para a continuidade dos estudos, a preparação básica para o

\footnotetext{
${ }^{1}$ Este artigo é parte de um projeto de pesquisa de mestrado em andamento no Programa de Pós-Graduação em Educação da Universidade Federal de Pernambuco.

2 UFPE, Recife, lanepereira.a@gmail.com

${ }^{3}$ UFPE, Recife, jamersonufpe@gmail.com
} 
trabalho e o exercício da cidadania. Esses três pilares, fundados por uma racionalidade própria do campo progressista, tomam o princípio educativo na relação entre o trabalho e a educação, em que "se afirma o caráter formativo do trabalho e da educação como ação humanizadora por meio do desenvolvimento de todas as potencialidades do ser humano" (CIAVATTA, 2009, s. p.). Seu campo de estudo está baseado no Materialismo Histórico da escola marxista e parte da concepção de trabalho como produtor dos meios de vida.

O trabalho como princípio educativo na formulação das leis educacionais no Brasil é resultado das lutas travadas pela sociedade civil organizada e esteve associado à discussão sobre a politecnia. A defesa em torno dessas formulações conceituais partiu de educadores brasileiros, pesquisadores da área trabalho e educação e tem por base algumas fontes básicas teórico-conceituais: no primeiro momento, a vertente marxista e gramsciana ${ }^{4}$ depois, "sem abrir mão da vertente gramsciana, a ontologia do ser social desenvolvida por Lukács" 5 (CIAVATTA, 2009, s. p.). Dentro desta perspectiva, a LDB destaca a unicidade entre as dimensões científica, tecnológica e cultural que parte da compreensão do trabalho em seu sentido ontológico.

No entanto a Lei, por si só, sem as necessárias reformas estruturais de base, não conseguiu arrefecer as investidas do capital internacional sobre a economia e a política brasileiras. Para permitir novas relações entre o capital e o trabalho, a dinâmica de desregulamentação provocada pelas reformas no aparelhamento estatal brasileiro conduziu alguns retrocessos no setor educacional: o Decreto n. $2 \cdot 208 / 97^{6}$, instituído um ano após da publicação da LDB, restabeleceu o dualismo formação geral/formação profissional, descaracterizando os princípios fundamentais da politecnia. Já as Diretrizes Curriculares Nacionais e os Parâmetros Curriculares Nacionais para o Ensino Médio, ambos editados nos anos finais da década de 1990, juntos promoveram a pedagogia das competências para a empregabilidade.

As primeiras discussões em torno da reestruturação do currículo do ensino médio, já no primeiro decênio dos anos 2000, facilitaram algum grau de participação dos coletivos em torno

\footnotetext{
${ }^{4}$ Marx; Gramsci (1981); Manacorda (1975 e 1990); Frigotto (1985); Kuenzer (1988); Machado (1989); Saviani (1989 e 1994); Nosella (1992); Rodrigues (1998) (CIAVATTA, 2009).

${ }^{5}$ Lukács (1978 e 1979); Konder (1980); Chasin (1982); Ciavatta Franco (1990); Antunes (2000); Lessa, (1996) (CIAVATTA, 2009).

${ }^{6}$ Revogado pelo Decreto 5.154/04 que possibilitou o estímulo à formação integrada.
} 
do tema. O documento "Reestruturação e Expansão do Ensino Médio no Brasil" (MEC, 2008), por exemplo, em muito contribuiu para o processo de atualização do currículo do ensino médio em 2012.

De acordo com o documento elaborado pelo GT

Busca-se uma escola que não se limite ao interesse imediato, pragmático e utilitário. Uma formação com base unitária, no sentido de um método de pensar e de compreender as determinações da vida social e produtiva - que articule trabalho, ciência e cultura na perspectiva da emancipação humana (MEC, 2008, p.8).

Contudo, o Parecer CNE/CEB no 5/2011, que versa sobre as Diretrizes Curriculares Nacionais para o Ensino Médio, apresenta as orientações em torno do trabalho como princípio educativo, mas indicando, contraditoriamente, que a formação deverá considerar as transformações provenientes da nova divisão internacional do trabalho, porque

para alcançar o pleno desenvolvimento, o Brasil precisa investir fortemente na ampliação de sua capacidade tecnológica e na formação de profissionais de nível médio e superior. Hoje, vários setores industriais e de serviços não se expandem na intensidade e ritmos adequados ao novo papel que o Brasil desempenha no cenário mundial, por se ressentirem da falta desses profissionais. Sem uma sólida expansão do Ensino Médio com qualidade, por outro lado, não se conseguirá que nossas universidades e centros tecnológicos atinjam o grau de excelência necessário para que o País dê o grande salto para o futuro (MEC, 2011, p.1, grifo nosso).

O currículo do ensino médio é, pois, um território de intensa disputa dentro das políticas educacionais brasileiras e, nesse sentido, a nossa questão central recai sobre o tipo de formação escolar que atravessa as concepções das políticas curriculares e seus impactos na preparação dos jovens estudantes para o mundo do trabalho e para a vida. Sob esse ponto de vista, este artigo se propõe a desvelar os sentidos produzidos pelo Programa Ensino Médio Inovador e a Política de Fomento às Escolas de Ensino Médio em Tempo Integral, considerando que os diferentes cenários de apropriação da racionalidade produtivista no campo educacional têm incidido negativamente na formação dos estudantes. Dessa forma, iniciamos a discussão problematizando os referenciais teórico-ideológicos das políticas curriculares em tela e, em 
seguida, demostramos como a sua aplicação vem ocorrendo na gestão do currículo das escolas de ensino médio com jornada ampliada em Pernambuco.

A jornada ampliada na escola pública não se trata de um projeto de curta durabilidade, "corresponde, de fato, ao movimento de reconfiguração da organização e operacionalização das redes e unidades de ensino público em todos os seus aspectos: político, social, administrativo e pedagógico" (SILVA, 2016, p.225). A Meta n. 6 do Plano Nacional de Educação "refere-se à educação em tempo integral e aponta para 50\% das escolas públicas, atendendo, até 2024, pelo menos, $25 \%$ dos estudantes da educação básica, com uma jornada mínima de 7 horas/diárias" (MOLL, 2018, p. 26). É nesse contexto que tanto o Programa Ensino Médio Inovador quanto a Política de Fomento às Escolas em Tempo Integral vêm apoiando a ampliação da oferta de ensino médio em tempo integral, nos estados e no Distrito Federal, através do repasse de recursos do Fundo Nacional de Desenvolvimento da Educação, FNDE, cujas formas de adesão estão vinculadas à reestruturação do currículo desta etapa da educação básica.

Operacionalmente, essas políticas curriculares passaram a responder às diretrizes do Governo Federal, as quais vincularam as demandas educacionais às políticas de responsabilização, próprias da racionalidade produtivista. Consideramos que esses aspectos concorreram para situar o campo educacional no caminho da nova relação entre o capital e o trabalho e, na organização curricular, provocaram a progressiva descaracterização da unicidade entre trabalho, ciência, tecnologia e cultura.

O estado de Pernambuco foi um dos pioneiros na oferta da educação em tempo integral no Brasil. Já em 2004, criou a rede dos Centros de Ensino Experimental, fruto de parceria público-privada, com o Instituto de Corresponsabilidade pela Educação, ICE. Este projeto de ensino médio em tempo integral vigorou até 2007, quando uma nova gestão do poder executivo desarticulou a parceria com o setor privado, criou o Programa de Educação Integral e passou a adotar as políticas de financiamento e reestruturação curricular do FNDE.

Com 366 Escolas de Referência em 2018, Pernambuco concentra a maior rede de ensino médio integral do país (PERNAMBUCO, 2018a) servindo como parâmetro institucional para outras redes de ensino, fato que nos desafia a questionar os mecanismos ideológicos que induzem ao "sucesso" da qualidade da educação no Brasil. 


\section{Os Programas do FNDE para o redesenho curricular do ensino médio: atravessamentos de} concepções e controle curricular

A racionalidade instrumental de mercado vem intensificando sua influência na legislação educacional brasileira por força das pressões de um modelo de governança pública, baseado em padrões quantificáveis de qualidade educacional distantes das propostas de caráter progressista defendidas pelos movimentos sociais. É desta maneira que, embora negociando formalmente as reinvindicações dos movimentos organizados, os planos de reestruturação curricular do ensino médio intensificaram a adequação do currículo ao novo padrão de acumulação capitalista.

Sendo assim, mesmo que inspirados a partir do postulado filosófico que conceitua a educação integral como a "superação das dicotomias entre humanismo e tecnologia, e entre a formação teórica geral e técnica-instrumental" (MEC, 2008, p.8), o Programa Ensino Médio Inovador, ProEMI, regulamentado pela Portaria no. 971, de 09/10/2009, e a Política de Fomento às Escolas de Ensino Médio em Tempo Integral (EMTI), Lei n. 13.415/177, têm se expressado em formas de organização curricular de atendimento à lógica capitalista.

O Programa Ensino Médio Inovador é um dos braços do Plano de Desenvolvimento da Educação (2007) como estratégia do Governo Federal para promover e estimular a inovação curricular no ensino médio (BRASIL, 2009), através de financiamento público ${ }^{8}$. Este Programa, por fornecer apoio técnico e financeiro às escolas de ensino médio, passou a ser, a partir de 2010, uma das principais linhas de financiamento para a oferta de ampliação do tempo nos sistemas de ensino. Dessa forma, ao prover recursos complementares importantes para as escolas, o ProEMI estendeu o campo de atuação para a oferta e implementação da educação integral no país, cenário que contribuiu para a desarticulação de experiências e projetos em andamento para a adoção de medidas ligadas às políticas federais (DOURADO, 2007).

As propostas do MEC em torno do Programa Ensino Médio Inovador têm como objetivo

\footnotetext{
${ }^{7}$ A Medida Provisória 746 editada em setembro de 2016, regulamentada pela Resolução FNDE no 4 de 25 de outubro neste mesmo ano, criou o Programa de Fomento às Escolas de Ensino Médio em Tempo Integral (EMTI).

${ }^{8}$ Como política de financiamento do ensino médio, o ProEMI compõe uma das ações do Programa Dinheiro Direto na Escola (PDDE) que destina recursos em caráter suplementar às Unidade Executoras (escolas) para manutenção e melhoria da infraestrutura física e pedagógica.
} 
a ampliação do tempo escolar, estimulando as redes de ensino que oferecem o ensino médio a criar "novas soluções que diversifiquem os currículos e promovam articulação interdisciplinar voltada para o desenvolvimento de conhecimentos, saberes, competências, valores e práticas" (MEC, 2009). A intenção por trás da proposta, segundo ainda o documento do MEC, é estimular as redes estaduais de educação a pensar novas formas de gerenciamento dos currículos com atividades integradoras, a partir dos eixos trabalho, ciência, tecnologia e cultura. Ao integrar esses Eixos, esta agenda política propõe uma síntese entre o conhecimento geral e o específico, tomando o conceito de trabalho como práxis humana.

No entanto, esta proposta é reveladora das ambivalências que sempre atravessaram o ensino médio no Brasil. Ao tempo em que defende uma posição em torno de uma escola com base unitária, que "articule trabalho, ciência, tecnologia e cultura na perspectiva da emancipação humana" (MEC, 2009), propõe, por outro lado, um currículo flexível e dinâmico que alinhe as expectativas e necessidades dos estudantes às demandas da sociedade atual, desenvolvendo "conhecimentos e habilidades associados a aspectos comportamentais (relacionamento, comunicação, iniciativa, cooperação, compromisso), relativos às atividades de gestão e de iniciativas empreendedoras" (MEC, 2009, p.10).

Já o EMTI foi criado dentro de um conjunto maior de mudanças no campo educacional que envolveu a reforma do currículo do ensino médio e a criação de uma Base Nacional Comum Curricular (BNCC), com o objetivo de alterar a Lei de Diretrizes e Bases, estabelecer mudança na estrutura do ensino médio e ampliar o tempo mínimo do estudante na escola, que passou a ser pelo menos 1000 (mil) horas anuais, com perspectiva de ampliação progressiva para mil e quatrocentas horas (BRASIL, 2017). A reforma do ensino médio e a criação da nova BNCC visam à garantia da oferta de educação de qualidade a todos os jovens brasileiros e à aproximação das escolas à realidade dos estudantes, considerando as novas demandas e complexidades do mundo do trabalho e da vida na sociedade contemporânea (MEC, 2018).

Dessa forma, tanto o ProEMI quanto o EMTI têm como ideia centralizadora a formação do jovem estudante a partir do referencial em torno do protagonismo juvenil e do projeto de vida que fazem parte de uma racionalidade que alarga o conceito de formação em face das novas demandas sociais. Para Kuenzer (2009), esse alargamento das dimensões formativas indica tratar-se agora não apenas de aprender conhecimentos e modos operacionais, mas de 
"saber, saber fazer, saber ser e saber conviver", agregando saberes cognitivos, psicomotores e socioafetivos. Nesses termos, espera-se do jovem estudante que ele seja capaz de elaborar um projeto de vida que lhe proporcione realização material e simbólica e assuma um compromisso ético e social com a comunidade da qual faz parte (DUTRA, 2019). Esta orientação está vinculada à visão do jovem como "ator estratégico do desenvolvimento", cuja proposta passa por "enfrentar os problemas de exclusão social aguda que ameaçam grandes contingentes de jovens e atualizar as sociedades nacionais para as exigências de desenvolvimento colocadas pelos novos padrões mundiais" (ABRAMO, 2005, p.21).

No entanto, o ator social por excelência é a ONG (Organização não governamental), que faz a intermediação entre os indivíduos e o cenário público, na oferta de um canal de participação (SOUZA, 2006). Segundo ainda a autora, é o projeto societário das ONGs, produzido e compartilhado pelos organismos multilaterais internacionais, que dá sustentação ideológica à formação/integração social da juventude. Nos últimos anos, são as ONGs uma das principais responsáveis em prescrever um currículo complementar ao currículo formal das escolas "com o objetivo de promover a transformação do jovem em ator social" (SOUZA, 2006, p.15). A própria noção de "projeto de vida" é um substrato referencial do modelo de escola da escolha, ideia partilhada pelos setores envolvidos com as ONGs.

O protagonismo juvenil é um elemento central para o tipo de participação social propagandeada pelo terceiro setor. A partir dele

Identificou-se uma matriz discursiva, ou em outros termos, um discurso explicativo do social, que concebe a sociedade como um aglomerado de atores sociais. Um discurso que homogeneíza o social na medida em que oculta as divisões de classe ou quaisquer outras: a sociedade seria composta por átomos, entre as quais não haveria relações de dominação, de poder ou exploração, mas relações de negociação (SOUZA, 2006, p.14).

Dito de outra forma, o protagonismo juvenil foi ideologicamente elaborado para "dissimular as relações de exploração capitalista, uma vez que institui um ambiente sem conflitos de classe, passível de negociação e mudança a partir da atuação direta do indivíduo" (SOUZA, 2006, p.14).

O empreendedorismo juvenil, conceito vinculado à cultura da trabalhabilidade, também 
vem sendo desenvolvido nas escolas e está ligado ao referencial do "aprender a fazer". Esse pilar formativo, por sua vez, está alinhado à agenda da UNESCO para a educação do século XXI, cujas orientações vêm ganhando forma nos debates sobre educação no Brasil.

As reformas curriculares para esta etapa da educação básica expressaram, em grande medida, as expectativas de um novo projeto de governo que se pautou na aliança estadomercado, cuja proposta criou terrenos ideológicos em favor da integração social juvenil. Essas representações teóricas em torno da juventude instituem um ambiente de positividade, onde se julga ser possível a transformação da sociedade pela atividade direta do indivíduo, enfoques que têm sido difundidos através de agências de cooperação internacional, de organismos multilaterais e de fundações empresariais "que vêm apoiando ações para jovens, e tem se traduzido, na maior parte das vezes, como a postulação dos jovens como protagonistas do desenvolvimento local" (ABRAMO, 2005, p.25).

Além desses redirecionamentos no campo conceitual, que afastam uma perspectiva mais progressista do currículo, no âmbito operacional os Programas se movimentam em favor da flexibilização das propostas curriculares. Essa estrutura de organização curricular permite a construção de currículos e propostas pedagógicas que atendam mais adequadamente às especificidades locais e à multiplicidade de interesses dos estudantes, (MEC, 2018). A flexibilização do currículo escolar opera, dessa forma, com múltiplos significados, notadamente o de descentralização e o de adequação/adaptação dos sistemas educativos (THIESEN, 2016). No entanto, alguns pontos divergentes em torno desses princípios são importantes destacar. A descentralização está associada à ideia de ampliação de autonomia, no entanto se movimenta em torno da política de resultados e do alcance de metas preestabelecidas. Já a adequação do currículo procura fixar um sentido de ampliação da liberdade de escolhas e de organização curricular, mas, "contraditoriamente, permite ao Estado e ao mercado educacional garantir maior agilidade aos processos formativos" (THIESEN, 2016, p.100), provocando o aligeiramento dos processos de formação.

Esta hibridização das concepções em tono do currículo está circunscrita, ainda, nas Diretrizes Curriculares Nacionais que trazem em sua proposta noções de currículo antagônicas, porque pressupõem vincular flexibilização curricular e formação por competências e habilidades com as dimensões estruturantes do currículo: trabalho, ciência, tecnologia e cultura. 
É a partir desta lógica produtivista que as políticas de reestruturação curricular vinculam a permanência da escola por meio de critérios de responsabilização. Para tanto, as escolas se mantêm vinculadas aos recursos mediante aferição positiva do fluxo escolar, medido pelas taxas de abandono e reprovação. Além disso, o MEC ainda poderá criar indicadores de desempenho adicionais, podendo aplicar as mesmas consequências de avaliação e desligamento previstas por lei (BRASIL, 2017). Nesta direção, será a União que estabelecerá os padrões de desempenho esperados para o ensino médio, que serão referências nos processos nacionais de avaliação. Esta centralização do currículo acaba por desconsiderar as variáveis nos sistemas de ensino e em suas instituições, padronizando a ação educativa, o que por princípio deveria ser diversificada.

As condições de governabilidade e a instituição de padrões de responsabilização são imprescindíveis para essas políticas. "Por esta perspectiva, a busca por resultados muda de foco e assume certa finalidade nem tanto social: apoiar ações voltadas ao desenvolvimento do mercado e não do cidadão" (CAVALCANTI; BOTLER, 2019, p.221). Assim, embora fundamentados pela concepção da participação da comunidade escolar, tanto o ProEMI quanto o EMTI, ao incluir os princípios de responsabilização, inverteram a lógica da participação coletiva nas escolas. A hibridização destas políticas no interior das escolas passa, pois, pela visão de participação atrelada a noções gerencialistas, de maneira que para o MEC as atividades deverão ser acompanhadas e avaliadas para garantir a boa e regular aplicação dos recursos das escolas. Situação que se aproxima mais do controle do trabalho pedagógico e menos da participação dos coletivos.

É importante destacar também que a partir de 2011 o setor privado se vinculou ao ProEMI, através de projetos e iniciativas com instituições privadas parceiras. Nesse contexto, o Instituto Unibanco, articulou o seu Programa Jovem de Futuro ao MEC, dando origem ao Ensino Médio Inovador/Jovem de Futuro (ProEMI/JF). O Projeto Jovem de Futuro formulou sua primeira proposta em 2006 e em 2007 o Programa foi implantado em quatro escolas da rede de ensino de São Paulo. A ação gerencialista, de acordo com o Instituto, é ofertar apoio financeiro e técnico às escolas públicas de ensino médio, com vista a promover a elevação dos índices de aprovação das escolas no Ideb. 
O ProEMI/JF capacita gestores e técnicos das Secretarias de Educação para apropriação das diretrizes da 'Gestão Escolar para Resultados' (INSTITUTO UNIBANCO, 2015). O principal mecanismo pedagógico do programa é a 'supervisão direta e intensiva' dos trabalhos do corpo gestor das escolas e a realização de exames comparativos visando acompanhar os níveis de desempenho cognitivo do corpo estudantil nos exames universais de aferição de aprendizagem (SILVA, 2016, p.129).

A pesquisa de Silva (2016) ainda indicou que o ProEMI apresentou dois movimentos estruturais e operacionais. O primeiro, que vigorou em 2009 e 2010, corresponde ao período que possibilitou maior flexibilidade de pedagogia e autonomia na elaboração das propostas curriculares diversificadas pelas escolas, pois se trata do momento anterior à instituição dos macrocampos. Nesse primeiro ciclo, a reformulação do currículo para o ensino médio deveria estar articulado pelos eixos trabalho, ciência e cultura. Já no segundo ciclo, a partir de 2011, a criação dos macrocampos limitou a elaboração das atividades nas escolas. Em outras palavras,

- Programa passa a prescrever um conjunto de atividades ligadas aos macrocampos, limitando, dessa forma, o poder de escolha das escolas, porque nesse novo cenário, o discurso deixa de ser indicativo e se torna prescritivo. Nesse sentido, ao criar limites para o formato pedagógico, os macrocampos viabilizaram a criação de processos mais padronizados de avaliação dos resultados da ação pelo MEC (SILVA, 2016, p.116).

Outra questão importante levantada pela autora é a desapropriação do conceito de "reestruturação" pelo termo "redesenho" curricular. Segundo sua pesquisa,

Em 2013, um documento Orientador do ProEMI, em versão preliminar, foi elaborado pelo MEC e enviado às Secretarias de Educação; depois da consulta, o texto final foi publicado com a substituição da expressão 'reestruturação curricular' por 'redesenho curricular' [...] É importante lembrar que esse movimento ocorreu um ano após a formulação do documento do Consed (Proposta para avanços no ensino médio) e da criação do ProEMI/JF [...]. O termo reestruturação carrega como sentido político a perspectiva de enfrentamento de questões sociais, não só pedagógicas, por meio das práticas escolares (SILVA, 2016, p.133).

Essas diretrizes de gerenciamento curricular ganharam forma nas composições das leis educacionais brasileiras através do discurso sobre eficiência, inovação e qualidade que passou 
a orientar a gestão dos serviços públicos, a partir dos anos de 1990.

Por acolhimento, sistemas e redes de ensino e escolas passam a operar na lógica destes princípios mobilizando redesenhos, readequações, ajustes, adaptações para os processos de ensino, aprendizagem, seleção dos repertórios de conhecimento, organização das matrizes curriculares, processos internos de avaliação, projetos pedagógicos, parcerias, formação continuada etc. (THIESEN, 2016, p.101).

As atividades integradoras do ProEMI e os itinerários formativos criados a partir do EMTI são ações curriculares que concorrem para a ampliação do tempo nas escolas. No entanto, elas partem de perspectivas diferentes de formação. As atividades integradoras, como o próprio nome indica, visam ampliar e integralizar o conteúdo do currículo do ensino médio. Já os itinerários formativos, ao trazerem a formação profissional, redimensionam a flexibilização curricular, que deverá ser organizada por meio da oferta de diferentes arranjos curriculares, conforme a relevância para o contexto local e a possibilidade dos sistemas de ensino" (MEC, 2018).

Dessa forma, os itinerários formativos cumprem esse papel na oferta de formação técnica e profissional, incluindo vivências práticas de trabalho no setor produtivo ou em ambientes de simulação que deverão ser realizadas na própria instituição ou em parceria com outras instituições, inclusive por meio de educação a distância ou educação presencial mediada por tecnologias (BRASIL, 2017).

Assim, os itinerários formativos, com foco nas áreas de conhecimento e na formação técnica e profissional, se relacionam com o Programa Novo Ensino Médio e são organizados a partir de quatro eixos estruturantes: Investigação Científica, Processos Criativos, Mediação e Intervenção Sociocultural e Empreendedorismo. Como podemos observar a intervenção sociocultural e o empreendedorismo são referenciais teóricos importantes que embasam esta política curricular para o ensino médio no Brasil. Dessa forma, a Portaria n. 1.432 de 28 de dezembro de 2018, que estabelece os referenciais para a elaboração dos itinerários formativos, entende que

Para participar de uma sociedade desafiada por questões socioculturais e ambientais cada vez mais complexas, os estudantes precisam se apropriar de conhecimentos e habilidades que os permitam atuar como agentes de 
mudanças e de construção de uma sociedade mais ética, justa, democrática, inclusiva, solidária e sustentável (MEC, 2018).

No entanto, defendemos neste trabalho o esvaziamento desses termos ao serem apropriados pelos discursos privatistas, porque a transformação convocada por eles não afetam as estruturas que fundam as desigualdades de classe. Além disso, essas propostas produzem modelos padronizados de juventudes, desconsiderando o ambiente com o qual o sujeito interage e se expressa em todas as suas dimensões (KLEIN; TORRES, 2015).

Trata-se, desse modo, de um cenário curricular, no qual "um conjunto de programas parece avançar na direção de políticas com caráter inclusivo e democrático, enquanto, de outro lado, prevalece a ênfase gerencial, com forte viés tecnicista e produtivista" (DOURADO, 2007, p.928). Então, ainda que fundamentado numa concepção de formação humanista e da participação coletiva, o currículo proposto pelas políticas curriculares analisadas neste estudo prevê também um conjunto de proposições que se vincula ao discurso do setor produtivo para o ensino médio.

É importante ressaltar que as diretrizes da Política de Fomento às Escolas de Ensino Médio em Tempo Integral, EMTI, correspondem a um retrocesso das lutas históricas pela democratização da educação básica que influenciaram em 2008 a construção do ProEMI, cuja proposta curricular, ainda que carregada de conflitos e encontrando dificuldade em se materializar na prática cotidiana das escolas, não se distanciou dos princípios republicanos reclamados pelos movimentos sociais.

Implica dizer que essas reformas curriculares fazem parte de um projeto de nação, disputado por visões que caminham em sentido contrário ao modelo de educação pública e democrática pensado pelos movimentos organizados na sociedade. Na verdade, as reformas não dialogam com as entidades imediatamente ligadas ao setor educacional, como o sindicato de professores e comunidade escolar. Por outro lado, os principais envolvidos neste processo

se apresentam como sujeitos individuais ou coletivos através de instituições públicas e privadas que atuam no setor educacional, institutos e fundações ligados a grandes empresas nacionais e internacionais, bem como instituições financeiras ligadas ao mercado de capitais, visando construir um projeto hegemônico de educação e de sociedade. (PERONI; CAETANO; LIMA. 2017, p.418). 
Para Chizzotti e Ponce (2012) a herança da tradição republicana no currículo não está esgotada, ela coexiste com a da tradição liberal. As duas tendências convivem em acordos e desacordos, incoerências e coerências, enfrentamentos e assimilações, caracterizando o cruzamento das concepções educacionais mencionadas neste estudo. O importante nesse processo é que não se perca o essencial das conquistas históricas relativas à escolarização e ao currículo das escolas. Isso inclui, de acordo com os autores, "valorizar os sujeitos envolvidos no processo curricular e não perder de vista e ampliar o direito à educação escolar" (CHIZZOTI; PONCE, 2012, p.25).

É nesse contexto que o ensino médio tem ocupado um papel de destaque nas discussões sobre educação no país. Assim, esta etapa da educação básica vem gerando propostas educacionais na forma de leis, de decretos e de portarias ministeriais que visam desde a inclusão de novas disciplinas e conteúdos aos currículos até a alteração na forma de financiamento da educação pública e de gestão curricular nas escolas.

\section{A gestão do currículo do ensino médio nas escolas em tempo integral de Pernambuco}

De acordo com o documento "Balanço da Educação 2015-2018", Pernambuco concentra a maior rede de ensino médio integral do País. Até este ano, a rede de escolas do Programa de Educação Integral de Pernambuco era composta por 366 Escolas de Referência em Ensino Médio, na oferta de ensino propedêutico, e 44 Escolas Técnicas Estaduais para a modalidade de ensino médio integral integrado à educação Profissional (PERNAMBUCO, 2018a). Dessa forma, ao menos uma escola em cada município funciona com este modelo de educação, ou seja, $100 \%$ dos municípios pernambucanos estão incluídos no Programa, inclusive no Arquipélago de Fernando de Noronha (PERNAMBUCO, 2017).

De acordo com Maria Medeiros, secretária executiva de Educação Integral e Profissional

os estudantes de escola integral têm um grande diferencial, pois podem ao longo dos três anos do Ensino Médio construir um conjunto de competências e habilidades, inclusive socioemocionais, que vão permitir tanto a continuidade aos estudos, ingressando em uma universidade, quanto a inserção produtiva no mundo do trabalho. (PERNAMBUCO, 2018a, p.31). 
As escolas do Programa de Educação Integral que ofertam ensino médio propedêutico se diferenciam em função do tempo, o que implica em modalidades diferentes de jornada na oferta de ensino médio integral. Dessa forma, a rede é composta por escolas em tempo integral, escolas semi-integrais e escolas semi-integrais de dois turnos.

Em relação às principais linhas de financiamento, a Secretaria Estadual de Educação atua no Ensino Médio em Tempo Integral com os Programas do Governo Federal, por meio do FNDE, entre os quais destacamos: o Plano de Desenvolvimento da Educação, o Programa Novo Mais Educação/PNME, o Programa Ensino Médio Inovador (ProEMI) e, a partir de 2018, a Secretaria de Educação aderiu à Política de Fomento às Escolas em Tempo Integral (EMTI). Esse conjunto de linhas de financiamento opera na "organização curricular na perspectiva da educação integral, a ampliação da jornada escolar através da oferta de atividades complementares e do fortalecimento do protagonismo juvenil" (PERNAMBUCO, 2017, p.117).

A ampliação da jornada escolar se dá por meio das Atividades Complementares e da Parte Diversificada do currículo das escolas que para a Secretaria de Educação deve compreender

o Protagonismo Juvenil e o Projeto de vida, a Educação Interdimensional e a Pedagogia da Presença, por meio de uma matriz curricular diferenciada e a oferta de componentes curriculares que promovam uma reflexão e fundamentos necessários para exercício de uma educação para valores que fomente o exercício da cidadania, que possibilite a formação de um jovem autônomo, solidário, criativo e produtivo (PERNAMBUCO, 2017, p.117).

Em 2012, a Secretaria de Educação do estado publicou a primeira matriz curricular da rede de escolas do Programa de Educação Integral. A carga horária das escolas com tempo integral $^{9}$ foi regulamentada em um total de 5.400 horas-aula, distribuídas entre os componentes da Base Comum Curricular, uma Parte Diversificada e as Atividades Complementares. Na Parte Diversificada estavam previstas as disciplinas Projeto de Empreendedorismo, Educação em Direitos Humanos, uma língua estrangeira moderna obrigatória e mais uma de livre escolha do aluno, perfazendo um total de $480 \mathrm{~h} / \mathrm{a}$. Já as

\footnotetext{
${ }^{9}$ Nas escolas semi-integrais, este documento fixou em 4.200 horas-aula para os três anos de ensino médio, distribuídas entre a Base Comum Curricular e uma Parte Diversificada (PERNAMBUCO, 2012).
} 
Atividades Complementares eram ofertadas com carga horária de dez horas-aula semanais, de cinquenta minutos, integrando um total de $1.200 \mathrm{~h} / \mathrm{a}$ no final do ensino médio e eram direcionadas às oficinas, projetos interdisciplinares, estudo e pesquisa. Dessa forma, as atividades que compunham a Parte Diversificada e as Atividades Complementares somavam 1.680 horas-aula do total geral previsto para compor o tempo da jornada ampliada nas escolas (PERNAMBUCO, 2012).

Já a partir de 2011, o currículo das EREMs passou a incluir, na sua Parte Diversificada, carga horária específica destinada ao componente curricular Projeto de Empreendedorismo. A Secretaria Estadual de Educação, em parceria com o Instituto de Corresponsabilidade pela Educação - ICE e Instituto Sonho Grande, dentro do Projeto Gestão da Qualidade Integral, elaborou o currículo de Empreendedorismo, propondo temáticas para formar jovens capazes de empreender na vida (PERNAMBUCO, 2017).

Segundo Dutra (2019), a cultura da trabalhabilidade, que integra o referencial do empreendedorismo, tem como proposta preparar o jovem para o mundo do trabalho, "desenvolvendo habilidades básicas e habilidades de gestão (autogestão, cogestão e heterogestão) e atitudes básicas diante da vida produtiva, como, por exemplo, o empreendedorismo" (DUTRA, 2019, p.40).

Como vimos anteriormente neste estudo, a proximidade entre protagonismo e empreendedorismo tem expressado a lógica empresarial dentro das escolas. Os discursos mercantilistas em torno desses dois conceitos deram origem a outros enunciados, que por vezes aparecem nos textos sobre a juventude em Pernambuco: resiliência, empoderamento, vulnerabilidade social, capital social e empreendedorismo social. Assim, protagonismo/empreendedorismo juvenil é "uma via de acesso ao discurso mais geral sobre o social, aquele que concebe a sociedade como um elenco de atores sociais em atuação num cenário público" (SOUZA, 2006, p.248). Sendo assim,

O jovem protagonista, 'ator principal' desse cenário público, apresentado pelo discurso como o 'agente e beneficiário da mudança', é o jovem objeto de políticas públicas que também deve oferecer sua contribuição ou sua contrapartida realizando atividades em benefício de si próprio e da coletividade (SOUZA, 2006, p.248). 
Em 2018, dentro de um contexto mais amplo de reformas no ensino médio, a Portaria SEE n. 910 reorganizou a matriz curricular para toda a rede. Segundo a Portaria, a Base Nacional Comum deverá ser acrescida por uma Parte Diversificada, na qual constem: Língua Estrangeira, Projeto de Vida e Empreendedorismo, Química Experimental, Física Experimental e Biologia Experimental (PERNAMBUCO, 2018b). Além disso, está previsto, na carga horária total de cada série, o conjunto das Atividades Complementares que compreendem estudo dirigido e aulas eletivas, estas últimas propostas pelos docentes, considerando os temas de interesse dos estudantes (DUTRA, 2019).

A figura de número 1, a seguir, demonstra como esses componentes curriculares estão distribuídos atualmente na Matriz Curricular das EREMs de jornada integral:

Figura 1: Matriz Curricular do Ensino Médio Integral em Pernambuco

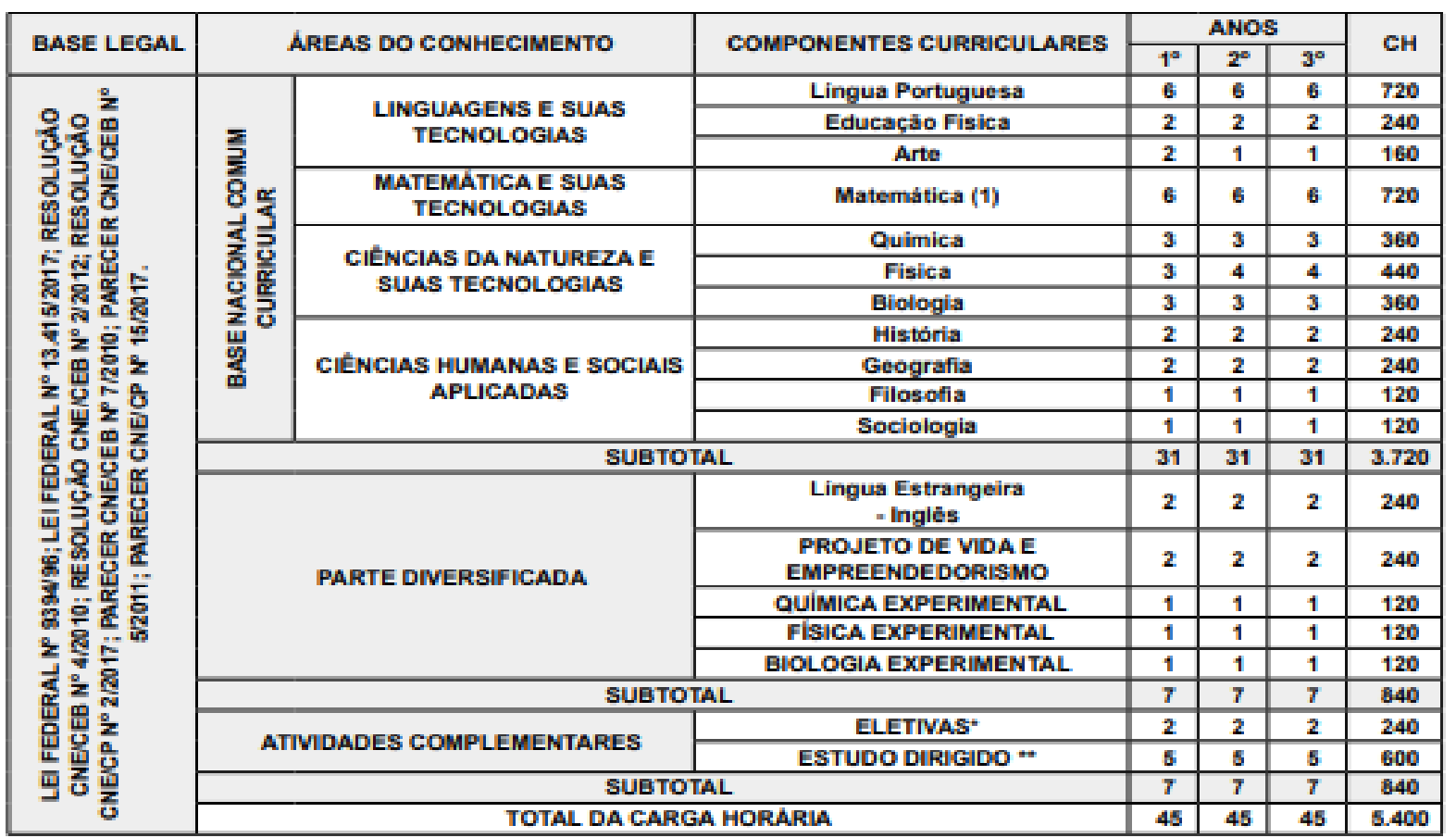

Fonte: Diário Oficial de Pernambuco n. 26 (PERNAMBUCO, 2018b).

As formas pelas quais o ensino médio em tempo integral da rede de Pernambuco vem se organizando revelam a disposição do atual momento da educação brasileira em acentuar uma formação voltada para o setor produtivo, estreitando o currículo nos componentes em que ele se apresenta mais aproximado da integração entre ensino, ciência e cultura. Alguns 
pontos são necessários destacar neste estudo.

Como demonstra a figura 1, a disciplina "Projeto de Vida e Empreendedorismo" compõe a Parte Diversificada da Matriz Curricular das EREMs, com carga horária total de 240 horas-aula para as escolas com jornada integral. Nas escolas de ensino médio integral, esta disciplina equivale à soma do tempo destinado às disciplinas de Filosofia e Sociologia como também é maior do que a carga horária prevista para as aulas de arte e as aulas de experimentos nos laboratórios. Além disso, tem carga horária equivalente às disciplinas de História, Geografia, Educação Física e Língua Estrangeira, dada a sua crescente importância para o currículo das EREMs.

A disciplina Direitos Humanos foi substituída pela disciplina Projeto de Vida e Empreendedorismo, cuja carga horária foi acrescida em 120 h/a. A Educação em Direitos Humanos é prevista formalmente pelas Diretrizes Curriculares para o Ensino Médio, DCNEM, no entanto, a SEE justifica essa substituição embasada no Decreto no 7037/200910, considerando que a Educação em Direitos Humanos será tratada transversal e integradamente, envolvendo todo o currículo. Consideramos esta substituição uma perda irreparável à formação do estudante, uma vez que o tema dos Direitos Humanos pode ser potencialmente capaz de produzir na sala de aula orientações no contrafluxo da lógica dominante.

A carga horária das aulas "Eletivas" foi introduzida na grade da Matriz destinada às "Atividades Complementares". Este eixo oferta Língua Estrangeira - Espanhol e atividades como projetos, oficinas, núcleos de estudo a que a Rede se refere como "Itinerários Formativos", em consonância com a estrutura do EMTI. Essas atividades podem ser escolhidas pelos estudantes "conforme seu interesse, para aprofundar e ampliar aprendizagens em uma ou mais Áreas de Conhecimento e/ou na Formação Técnica e Profissional” (MEC, 2018). Em 2010, no entanto, as eletivas com base no Art. 17 da Resolução CNE/CEB no 4/2010, não previam a formação técnica e profissional, mas práticas interdisciplinares, cuja contextualização deveria assegurar a interlocução entre os saberes e os diferentes campos do conhecimento (BRASIL, 2010). Entendemos que essa orientação poderia envolver práticas curriculares mais aproximadas da formação integral do estudante.

Assim, a diminuição da carga horária prevista para as Atividades Complementares em

${ }^{10}$ Aprova o Programa Nacional de Direitos Humanos - PNDH-3 e dá outras providências. 
favor das disciplinas da Parte Diversificada deixou de favorecer por um lado, a diversificação de atividades escolares, geralmente orientadas, pelo desenvolvimento das dimensões estéticas, sociais e culturais dos estudantes, e por outro lado, uma maior organização do coletivo escolar, a quem cabia definir as estratégias de aprendizagens para este espaço curricular. Dessa forma, nos termos da carga horária destinada à ampliação do tempo nas escolas integrais, a atual versão da Matriz Curricular manteve o número de aulas previsto para a Base Curricular Comum (3.720 h/a), aumentou em 360h/a a Parte Diversificada do currículo, direcionando esta carga horária para as atividades de laboratório em prejuízo das Atividades Complementares que, agora, integram apenas o Estudo Dirigido e as Atividades Eletivas, componentes curriculares previsto pelo Programa Novo Ensino Médio.

Em relação ao estudo de línguas estrangeiras, verificamos a centralidade em torno da língua inglesa no atual currículo, uma vez que o ensino da língua espanhola passou a ser oferecido de forma opcional, após a reforma curricular do ensino médio.

Em síntese, tivemos neste período a substituição da disciplina Direitos Humanos pelo componente curricular Projeto de Vida e Empreendedorismo de viés mercantilista, o estreitamento das aulas de Línguas Estrangeiras e dos Projetos Interdisciplinares em razão da diminuição da carga horária prevista para as Atividades Complementares e a inclusão dos Itinerários Formativos, que em detrimento da valorização dos conteúdos disciplinares e a interdisciplinaridade entre os campos do conhecimento, reforçam a educação profissional.

Acreditamos que no período que compreendeu a matriz curricular das EREMs, editada em 2012 com a inclusão das orientações do ProEMI, até a edição da nova matriz de 2018 em razão da Política de Fomento às Escolas em Tempo Integral, a Secretaria de Educação do Estado e o Programa de Educação Integral redimensionaram as orientações privatistas no currículo, onde o ensino escolar se voltou de forma mais proeminente para atender as mutações da relação capital-trabalho.

\section{Considerações Finais}

Ainda que fundada por princípios republicanos, a Lei de Diretrizes e Bases da Educação não conseguiu arrefecer a racionalidade instrumental de mercado que vem intensificando sua 
influência por meio dos planos de reestruturação curricular do ensino médio para a adequação do currículo ao novo padrão de acumulação capitalista. Como foi possível observar, o ProEMl e o EMTI estão enviesados por dispositivos mercadológicos, uma vez que consideram a avaliação como parte estrutural do currículo; vinculam a permanência nos Programas a indicadores de desempenho; intensificam a flexibilização do currículo, reforçam práticas educativas ligadas ao contexto produtivo local e, no caso apenas do EMTI, formaliza a educação a distância. Componentes que em seu conjunto relativizam os diferentes contextos de desigualdade dos sistemas de ensino no Brasil e aprofundam o problema em torno da inclusão/exclusão educacional e social.

Em termos conceituais, as orientações curriculares vêm sofrendo progressiva interferência do mercado ao se aproximar dos referenciais teórico-ideológicos do protagonismo juvenil, empreendedorismo e projeto de vida. De forma geral, essas prescrições curriculares reforçam a noção de transformação individual e social pela atividade direta do indivíduo, desconsiderando as estruturas de desigualdade às quais inúmeros estudantes estão submetidos. Essas circunstâncias redirecionaram as orientações com potencial para desenvolver nas escolas as dimensões estruturantes do currículo: trabalho, ciência, tecnologia e cultura.

A rede de educação em tempo integral de Pernambuco, ao introduzir no currículo do ensino médio essas orientações, explicitou a sua vinculação pedagógica com o projeto societário, ou especificamente de juventude, em curso no Brasil. Movimento que demandou progressivas reformulações na Matriz Curricular da Rede em favor desta dinâmica.

A construção de alternativas educativas que alarguem as possibilidades de resistência ao que está prescrito pelo currículo do ensino médio hoje é, pois, tarefa urgente, passível de ser alcançada pelo fortalecimento da ação conjunta e do diálogo permanente dentro das escolas.

\section{Referências}

ABRAMO, H. W. O uso das noções de adolescência e juventude no contexto brasileiro. In: FREITAS, M. V. (org.). Juventude e adolescência no Brasil: referências conceituais. São Paulo: Ação educativa, 2005, p.19-39. Disponível em: https://library.fes.de/pdffiles/bueros/brasilien/05623.pdf. Acesso em: 30 nov. 2019. 
BRASIL. Portaria no 971, de 9 de outubro de 2009. Instituir, no âmbito do Ministério da Educação, o Programa Ensino Médio Inovador. Diário Oficial da União: seção 1, Brasília, DF, n.195, p.52, 13 out. 2009.

BRASIL. Lei n. 13.415 de 16 de fevereiro de 2017. Institui a Política de Fomento à Implementação de Escolas de Ensino Médio em Tempo Integral. Brasília, DF: Presidência da República, 2017. Disponível em: http://www.planalto.gov.br/ccivil_03/_ato20152018/2017/lei/l13415.htm. Acesso em 20 set. 2019.

BRASIL. Lei no 13.005, de 25 de junho de 2014. Aprova o Plano Nacional de Educação (PNE) e dá outras providências. Brasília: Diário Oficial [da] República Federativa do Brasil, Brasília, 26 jun. 2014. Seção 1, p. 1, Ed. Extra.

BRASIL. Conselho Nacional de Educação. Resolução CNE/CEB n 4, de 13 de julho de 2010. Diretrizes Curriculares Nacionais Gerais para a Educação Básica. Brasília, Diário Oficial [da] República Federativa do Brasil, 14 de julho de 2010, Seção 1, p. 824, 2010.

BRASIL. Conselho Nacional de Educação. Parecer CNE/CEB no 05/2011. Diretrizes Curriculares Nacionais para o Ensino Médio, Brasília, DF: Conselho Nacional de Educação, Câmara de Educação Básica, 2011. Disponível em: http://portal.mec.gov.br/index. php?option=comcontent\&id=12992:diretrizes-para-a-educacao-basica. Acesso em: 23 set. 2019.

CAVALCANTI, A. C. D.; BOTLER A. M. H. Razão instrumental no contexto da reforma administrativa em Pernambuco: como fica a participação cidadã? In: SANTOS, A. L. F.; ANDRADE, E. F. M.; ROSA, L. (orgs.). Políticas educacionais no estado de Pernambuco: discursos, tensões e contradições. Recife: UFPE, 2019. Disponível em: http://www.seminariosregionaisanpae.net.br/BibliotecaVirtual/10Livros/PoliticaEducacionalPernambuco.pdf. Acesso em: 3 dez 2019.

CHIZZOTI, A.; PONCE, B. J. O currículo e os sistemas de ensino no Brasil. Currículo sem Fronteiras, v.12, n.3, p.25-36, set./dez. 2012. Disponível em: http://www.curriculosemfronteiras.org/vol12iss3articles/chizzotti-ponce.pdf. Acesso em: 20 dez. 2019.

CIAVATTA, M. Trabalho como princípio educativo. Dicionário da educação profissional em saúde, Fiocruz, Rio de Janeiro, s. p., 2009. Disponível em: http://www.sites.epsjv.fiocruz.br/dicionario/verbetes/trapriedu.html. Acesso em: 20 set. 2019.

DOURADO, L. F. Políticas e gestão da educação básica no Brasil: limites e perspectivas. Educação \& Sociedade, Unicamp, Campinas, v.28, n.100, p.921-946, 2007. Disponível em: http://www.scielo.br/pdf. Acesso em: 07 set. 2019.

DUTRA, P.F. V. PROGEPE: módulo de educação integral e profissional. 2. ed. Recife: Secretaria de Educação e Esportes de Pernambuco, 2019. 
KLEIN, A. M.; TORRES, J. C. Educação, projetos de vida e participação política da juventude. Ponto e vírgula, São Paulo, n.17, p.251-269, 2015. Disponível em: https://revistas.pucsp.br/pontoevirgula/about/contact. Acesso em: 30 dez 2019.

KUENZER. A. Z. Ensino médio: construindo uma proposta para os que vivem do trabalho. 6. ed. São Paulo: Cortez, 2009.

MEC. Reestruturação e expansão do ensino médio no Brasil (GT Interministerial instituído pela Portaria no. 1189 de 05 de dezembro de 2007 e a Portaria no. 386 de 25 de março de 2008). Brasília, DF: MEC-Secretaria de Assuntos Estratégicos da Presidência da República, 2008. Disponível em: http://portal.mec.gov.br/seb/arquivos/pdf/2008/interministerialresumo2.pdf. Acesso em: 30 nov. 2019.

MEC. Programa Ensino Médio Inovador: documento orientador. Brasília, DF: Secretaria de Educação Básica. 2009. Disponível em:

http://portal.mec.gov.br/dmdocuments/documento_orientador.pdf. Acesso em: 30 nov. 2019.

MEC. Resolução n. 1.432, de 28 de dezembro de 2018. Estabelece os referenciais para elaboração dos itinerários formativos conforme preveem as diretrizes nacionais do ensino médio. Diário Oficial da União: Seção 1, Brasília, DF, edição n.66, p.94, 5 abr. 2019.

MOLL, J. Educação Integral. In: OLIVEIRA, J. F.; GOUVEIA, A.B.; ARAÚJO, H. (Orgs). Caderno de Avaliação das Metas do Plano Nacional de Educação: PNE 2014-2024. ANPAE, Brasília, 2018. Disponível em: https://www.anpae.org.br/BibliotecaVirtual/4-

Publicacoes/CadernoAnlisePNE.pdf. Acesso em: 10 dez. 2019.

PERNAMBUCO. Instrução Normativa ${ }^{\circ}$ 01, de 28 de fevereiro de 2012. Diário Oficial do Estado de Pernambuco: Poder Executivo, Pernambuco, ano 89, n.38, p.8-11, 28 fev. 2012.

PERNAMBUCO. Relatório Anual de Indicadores 2017: Lei de Responsabilidade Educacional. Pernambuco: Secretaria de Educação do Estado, 2017. Disponível em: http://www.alepe.pe.gov.br/wp-content/uploads/2018/08/RELATORIO-ANUAL-EDUCACAO2017.pdf. Acesso em: 04 de dez. 2019.

PERNAMBUCO. Balanço da educação: 2015-2018. Pernambuco: Secretaria de Educação do Estado de Pernambuco, 2018a. Disponível em: http://www.educacao.pe.gov.br/portal/upload/galeria/15373/BALAN\%C3\%870\%20DA\%20ED UCA\%C3\%87\%C3\%830\%202015-\%202018.pdf. Acesso em 05 dez. 2019.

PERNAMBUCO. Portaria no 910, de 06 de fevereiro de 2018. Matrizes Curriculares das Escolas de Referência em Ensino Médio jornada Integral, Semi-Integral e das Escolas Técnicas Estaduais ofertantes do Ensino Médio integrado à Educação Profissional. Diário Oficial do Estado de Pernambuco: Poder Executivo, Pernambuco ano 95, n.26, p.6-7, 7 fev. 2018b

PERONI, V. M. V.; CAETANO, M. R.; LIMA, P. V. Reformas educacionais de hoje: as implicações 
para a democracia. Revista Retratos da Escola: CNTE, Brasília, v.11, n.21, p.393-413, jul./dez. 2017. Disponível em:

https://www.cnte.org.br/images/stories/retratos_da_escola/retratos_da_escola_21_2017.pdf Acesso em 3 dez. 2019.

SILVA, A. G. A. Ensino (em tempo) integral: as propostas oficiais na dinâmica do real. 2016. 325f. Tese (Doutorado em Educação) - Programa de Pós-Graduação em Educação do Centro de Educação, UFPE, Recife, 2016.

SOUZA, R. M. O discurso do protagonismo juvenil. 2006. 350f. Tese (Doutorado em Sociologia) Programa de Pós-Graduação em Sociologia da Faculdade de Filosofia, Letras e Ciências Humanas, USP. São Paulo, 2006.

THIESEN, J. S. A gestão do currículo nas malhas das redes políticas em escala transnacional. Revista Teias, PROPED: UERJ, Rio de Janeiro, v.17, n.47, p.91-106, out.-dez. 2016. Disponível em: https://www.e-publicacoes.uerj.br/index.php/revistateias. Acesso em: 30 mar. 2020.

Recebido em maio 2020.

Aprovado em dezembro 2020. 